\title{
Burden and coping strategies among caregivers of patients with mood disorders
}

\author{
Wageeh Abdel - Nasser Hassan, Ikram Ibraheem Mohamed, \& Nadia Ebraheim Sayed.
}

Prof. of, Psychiatry, Faculty of Medicine, Assuit University. Assistant Prof, of Psychiatric Nursing, Faculty Nursing Assiut University.

Assistant Prof, of psychiatric Nursing, Faculty of, Nursing, Assiut University.

\begin{abstract}
The study aimed to investigate burden and coping strategies among caregivers of patients with mood disorder and examine the relationship between them. A descriptive correlational design was utilized. The study was carried out at inpatient unit at neuropsychiatry and neurosurgical hospital at Assiut University. A convenient sample comprised of 100 caregivers of patients with mood disorder. Tools of study comprised of personal data questionnaire, mood disorder burden index and ways of coping questionnaire. Results: The highest mean scores of burden of exhibited specific behaviors by patients were related to sleeping too much, there were too many thoughts running through patients' head and they were more talkative than usual. The highest mean scores of coping strategies were related to self-controlling, positive reappraisal and seeking social support respectively. Self-controlling, planful problem solving and positive reappraisal were positively and significantly correlated with frequency of exhibited specific behaviors by patients. Conclusion: Caregivers experienced high mean scores of burden related to the frequency of symptoms exhibited by patients. The highest mean scores of coping strategies utilized by them were related to selfcontrolling, positive reappraisal and seeking social support. Self-controlling, planful problem solving and positive reappraisal were positively and significantly correlated with some of exhibited specific behaviors by patients. Recommendations: Designing and implementing psychoeducational programs are essential for caregivers of patients with mood disorders.
\end{abstract}

Key words: Caregivers, burden, coping strategies and mood disorder patients.

\section{Introduction}

Caregiving is a dynamic process which includes patient and a person who is involved in long term care of the patient. This long term care very often leads to experience of burden in the caregivers Recent years have seen increasing awareness of the role of caregivers in the long-term management of psychiatric patients, and there is growing body of literature on the caregiver burden, poor caregiver outcomes, lack of caregiver support, and equivocal success, with interventions aimed at alleviating the care-giving burden. It has also become clear that the emphasis in psychiatric rehabilitation needs to shift from a patient-focused approach to a combined patient and caregiver focused approach (Pratima et al., 2011).

The term "caregiver burden" is used to describe the physical, emotional and financial toll of providing care. The burden perceived by caregivers of patients with psychiatric illness is a fundamental prognostic aspect as the caregiver burden is reportedly a critical determinant for negative caregiving outcomes (Ampalam et al., 2012).

Caregiver burden is a multi-faceted construct, which may be associated with a number of variables: patient problem behavior, changes in caregiver and patient functioning, social support networks, caregiver coping and attributional styles, family or relationship functioning, perceived stigma and caregiver

psychiatric symptoms (Reinares and Vieta, 2004). Various studies have explored the impact of these variables on perceived burden on caregiver and patient outcomes. Some of these studies suggest that caregivers of patients with bipolar disorder exhibit high rates of anxiety, depression and mental health service use, and that these conditions may be associated with elevated rates of caregiver burden (Perlick et al., 2005, 2007a).

Davenport (2008) found that, objective and subjective caregiver burden were significantly increased in caregivers looking after patients with recent episodes of depression, but not recent episodes of mania/ hypomania/ mixed states, in comparison with those caring for patients who had recovered from a mood episodes prior to assessment. Objective burden was significantly associated with fewer days well, depression symptom score, patient's socioeconomic status, and whether the patient and caregiver lived together, while subjective burden was significantly associated with fewer days well and whether the patient and caregiver lived together. Even after controlling for days well objective burden was significantly associated with patient depression. On the other hand, Moller-Leimkuhler and 
Obermeier (2008) reported that, expressed emotion, neuroticism, generalized negative stress response and life stressors resulted as the best predictors of burden. In this respect, Scazufca \& Kuipers (1999) reported that, it is important to understand caregiver's coping strategies for tackling burden, because it affects not only caregiver's day-to-day functioning and is a constant source of stress, but how this stress is managed also has a bearing on the course of person's illness and prospects for improvement.

Available evidence suggests that problem-focused coping strategies and low level of criticism (implying low level of expressed emotions) are related to lower values of family burden (Chakrabarti \& Gill, 2002 \& Moller-Leimkuhler, 2005). In this respect, Östman and Hansson (2001) observed that the preference for task-focused coping strategies in families of patients with bipolar disorder was related to lower levels of family burden and lower rates of chronicity, while emotion-focused coping strategies are bound to persistence of symptoms or lack of changes in patients' behaviors.

\section{Significance of study:}

Pratima et al., (2011) reported that bipolar disorder is associated with a high degree of chronicity and disability, and caregivers experience a significant burden, which is, in turn, associated with poorer clinical outcomes for the patients. Identification of the caregivers' coping strategies may aid in helping them cope with their situation. Understanding how the caregivers copes with their situation is essential in tackling burden and providing the best outcomes for the entire family.

Aims of study:

1. To investigate burden and coping strategies among caregivers of patients with mood disorder.

2. To examine the relationship between burden and coping strategies among caregivers of patients with mood disorder.

Subjects and method:

Design: A descriptive correlational design was utilized in this study.

Setting: The study was carried out at inpatient unit at neuropsychiatry and neurosurgical hospital at Assiut University.

Sample: A convenient sample comprised of 100 caregivers of bipolar patients with the following criteria:

The caregiver must be between more than 15 to 75 years old.

The caregiver must be from first or second degree relatives.

\section{Tools of study:}

1.Personal data questionnaire which comprised of age, sex, marital status......etc.
2. Mood Disorder Burden Index (MDBI): This index was developed by Martire et al., (2009) to assess the frequency of burden among caregivers of mood disorder patients. Caregivers were asked to report how often the patient had exhibited specific behaviors (1-23), or how often the caregivers had specific experiences related to the patient (24-32), in the past month.

A Frequency was rated on the following scale: $0=$ never, $1=$ sometimes, $2=$ quite frequently, $3=$ nearly always. Values are based on data from caregivers who reported that the event occurred in the past month.

B Bother or upset was rated on the following scale: $0=$ not at all, $1=$ a little, $2=$ moderately, $3=$ very, 4 = extremely. Values are based on data from caregivers who reported that the event occurred in the past month.

Frequency scores are calculated by summing across all frequency items. Reaction scores are calculated by summing scores across all reaction items and assigning 0 (not at all bothersome/upsetting) to events that did not occur.

3. Ways of coping questionnaire (revised form): It used to assess caregivers coping strategies. It was developed by Folkman et al in 1986. It consists of 66 items. These items are classified into 8 coping subscales as the following: Confrontive coping, distancing, self-controlling, seeking social support, accept responsibility, escape/avoidance, planful problem-solving and positive reappraisal. The subjects responded on a 4-point Likert scale $(\mathrm{o}=$ does not apply and/or not used; $3=$ used a great deal).

The previous tools were translated into Arabic language to suit caregivers' culture and validity was done by jury from 5 experts in the field of psychiatric nursing and psychiatric medicine.

\section{Procedure:}

- An official permission was granted from the head of psychiatric unit at neuropsychiatry and neurosurgical hospital at Assiut University to carry out study.

- The purpose of the study was explained to caregivers of mood disorder patients and verbal consent was taken from those who agreed to participate in the study.

A pilot study: The pilot study was carried out on 10 caregivers of patients with mood disorder to ensure clarity of the study tools. They were included in the study because there no any modification was done.

Ethical consideration: Ethical approval for the protocol of research was obtained from post graduate and research committee in the faculty of nursingAssiut University. The researchers obtained informed consent for participation from caregivers of mood disorder patients after they were provided with a 
detailed description of the study and were assured of the confidentiality of information obtained.

\section{Statistical Analysis:}

The collected data were coded, categorized, and then analyzed using the statistical package for social science (SPSS) version 16. Descriptive statistics were calculated as frequency, percentage, mean, standard deviation and Pearson correlation were used to test the associations between study variables. Probability (p-value) is considered significant at or less than 0.05 .

\section{Results}

Table (1) : Socio-demographic characteristics of the caregivers of patients with mood disorders.

\begin{tabular}{|c|c|c|}
\hline & No. $(n=100)$ & $\%$ \\
\hline \multicolumn{3}{|l|}{ Age: } \\
\hline$<30$ years & 22 & 22.0 \\
\hline $30-<40$ years & 21 & 21.0 \\
\hline $40-<50$ years & 25 & 25.0 \\
\hline$\geq 50$ years & 32 & 32.0 \\
\hline Mean \pm SD (Range) & \multicolumn{2}{|c|}{$42.57 \pm 13.54(16-75)$} \\
\hline \multicolumn{3}{|l|}{ Sex: } \\
\hline Males & 47 & 47.0 \\
\hline Females & 53 & 53.0 \\
\hline \multicolumn{3}{|l|}{ Marital status: } \\
\hline Single & 22 & 22.0 \\
\hline Married & 67 & 67.0 \\
\hline Divorced & 1 & 1.0 \\
\hline Separated & 10 & 10.0 \\
\hline \multicolumn{3}{|l|}{ Level of education: } \\
\hline Illiterate/ Read \& write & 51 & 51.0 \\
\hline Basic education & 9 & 9.0 \\
\hline Secondary & 29 & 29.0 \\
\hline University & 11 & 11.0 \\
\hline \multicolumn{3}{|l|}{ Occupation: } \\
\hline Employee & 31 & 31.0 \\
\hline Unemployed & 17 & 17.0 \\
\hline Farmer & 12 & 12.0 \\
\hline Housewife & 40 & 40.0 \\
\hline \multicolumn{3}{|l|}{ Consanguinity level: } \\
\hline First degree & 79 & 79.0 \\
\hline Second degree & 21 & 21.0 \\
\hline \multicolumn{3}{|l|}{ Residence: } \\
\hline Rural & 35 & 35.0 \\
\hline Urban & 65 & 65.0 \\
\hline
\end{tabular}


Table (2) : Distribution of the mean scores and standard deviations of mood disorder burden index among caregivers of patients with $\operatorname{mood}$ disorders $(n=100)$.

\begin{tabular}{|c|c|c|}
\hline \multirow[t]{2}{*}{ Mood Disorder Burden Index (MDBI) Items } & $\begin{array}{l}\text { Frequency } \\
(\mathbf{1}-\mathbf{3}) \mathbf{a}\end{array}$ & $\begin{array}{l}\text { Bother or upset } \\
\quad(1-4) b \\
\end{array}$ \\
\hline & Mean \pm SD & Mean \pm SD \\
\hline 1. Patient was sad or tearful & $1.33 \pm 1.57$ & $1.36 \pm 1.27$ \\
\hline 2. Patient had less interest or pleasure in activities & $1.58 \pm 1.48$ & $1.57 \pm 1.24$ \\
\hline 3. Patient gained or lost weight, or had a significant change in appetite & $1.51 \pm 1.51$ & $1.55 \pm 1.23$ \\
\hline 4. Patient slept too much & $0.61 \pm 1.19$ & $0.62 \pm 1.06$ \\
\hline 5. Patient slept too little & $2.45 \pm 1.52$ & $2.25 \pm 1.15$ \\
\hline 6. Patient was restless or agitated & $1.95 \pm 1.45$ & $1.90 \pm 1.08$ \\
\hline 7. Patient was tired or had no energy & $1.14 \pm 1.43$ & $1.19 \pm 1.16$ \\
\hline 8. Patient talked about feeling worthless or guilty & $1.20 \pm 1.49$ & $1.26 \pm 1.19$ \\
\hline 9. Patient had trouble concentrating, making a decision, or remembering things & $1.72 \pm 1.48$ & $1.79 \pm 1.12$ \\
\hline 10. Patient said that life is not worth living & $1.13 \pm 1.41$ & $1.14 \pm 1.18$ \\
\hline 11. Patient threatened to hurt him/herself & $1.06 \pm 1.33$ & $1.03 \pm 1.12$ \\
\hline 12. Patient did not take care of his/her physical appearance or personal hygiene & $1.33 \pm 1.44$ & $1.29 \pm 1.22$ \\
\hline 13. Patient was very egotistic or self- centered & $0.96 \pm 1.20$ & $1.03 \pm 1.08$ \\
\hline 14. Patient was more talkative than usual & $2.05 \pm 1.51$ & $1.97 \pm 1.15$ \\
\hline 15. Patient said there were too many thoughts running through his/her head & $2.05 \pm 1.51$ & $1.98 \pm 1.16$ \\
\hline 16. Patient was easily distracted or unable to pay attention & $1.88 \pm 1.44$ & $1.97 \pm 1.11$ \\
\hline 17. Patient took on a lot more activities than usual & $1.68 \pm 1.48$ & $1.69 \pm 1.21$ \\
\hline $\begin{array}{l}\text { 18. Patient spent a lot of money, made foolish business investments, or was more } \\
\text { sexually interested or active than usual }\end{array}$ & $1.14 \pm 1.37$ & $1.18 \pm 1.19$ \\
\hline 19. Patient used alcohol or other substances because of mood problems & $0.52 \pm 1.08$ & $0.50 \pm 0.94$ \\
\hline $\begin{array}{l}\text { 20. Patient had difficulty working, caring for the home, or other activities that } \\
\text { he/she is normally responsible for }\end{array}$ & $1.48 \pm 1.46$ & $1.59 \pm 1.20$ \\
\hline $\begin{array}{l}\text { 21. Patient skipped doses of psychiatric medication or took the medication in the } \\
\text { wrong way }\end{array}$ & $0.89 \pm 1.17$ & $1.04 \pm 1.06$ \\
\hline 22. Patient had side effects from his/her psychiatric medication & $0.53 \pm 0.89$ & $0.65 \pm 0.85$ \\
\hline $\begin{array}{l}\text { 23. Patient was reluctant to go for, or refused to keep, his/her medical } \\
\text { appointments for mood disorder }\end{array}$ & $1.14 \pm 1.35$ & $1.19 \pm 1.18$ \\
\hline $\begin{array}{l}\text { 24. Caregiver had difficulty contacting or communicating with mental health care } \\
\text { providers in regard to Patient's treatment for mood disorder }\end{array}$ & $1.89 \pm 1.48$ & $1.98 \pm 1.07$ \\
\hline $\begin{array}{l}\text { 25. Caregiver had difficulty paying for medications, medical appointments, or } \\
\text { dealing with health insurance related to patient's treatment for mood disorder }\end{array}$ & $1.98 \pm 1.56$ & $1.93 \pm 1.17$ \\
\hline 26. Caregiver had to tell friends or relatives about patient's mood disorder & $1.44 \pm 1.36$ & $1.51 \pm 1.19$ \\
\hline $\begin{array}{l}\text { 27. Caregiver thought about the possibility that patient may continue to have } \\
\text { mental health problems }\end{array}$ & $1.90 \pm 1.35$ & $2.07 \pm 0.95$ \\
\hline 28. Caregiver thought about own mental health, or that of children or siblings & $1.36 \pm 1.38$ & $1.46 \pm 1.15$ \\
\hline $\begin{array}{l}\text { 29. Caregiver had arguments or conflict with patient as a result of patient's mood } \\
\text { disorder }\end{array}$ & $1.84 \pm 1.39$ & $1.90 \pm 1.11$ \\
\hline $\begin{array}{l}\text { 30. Caregiver felt that patient had withdrawn from caregiver as a result of } \\
\text { patient's mood disorder }\end{array}$ & $2.02 \pm 1.46$ & $2.10 \pm 1.01$ \\
\hline $\begin{array}{l}\text { 31. Caregiver felt that efforts to be helpful to patient when patient was having } \\
\text { mood problems were rejected }\end{array}$ & $2.03 \pm 1.40$ & $2.06 \pm 1.05$ \\
\hline $\begin{array}{l}\text { 32. Caregiver felt a loss of companionship or closeness with patient as a result of } \\
\text { patient's mood disorder }\end{array}$ & $2.01 \pm 1.52$ & $2.03 \pm 1.20$ \\
\hline
\end{tabular}


Table (3): Mean scores and standard deviations of coping strategies among caregivers of patients with mood disorders.

\begin{tabular}{|l|c|c|}
\hline \multicolumn{1}{|c|}{ Coping Strategies } & Mean \pm SD & Range \\
\hline 1. Confrontive coping & $7.02 \pm 2.79$ & $0-17$ \\
\hline 2. Distancing & $8.22 \pm 3.12$ & $3-16$ \\
\hline 3. Self-controlling & $9.89 \pm 4.01$ & $1-21$ \\
\hline 4. Seeking social support & $9.25 \pm 4.43$ & $2-18$ \\
\hline 5. Accepting responsibility & $3.37 \pm 2.04$ & $0-11$ \\
\hline 6. Escape avoidance & $8.52 \pm 2.96$ & $3-16$ \\
\hline 7.Planful problem solving & $7.26 \pm 3.68$ & $1-17$ \\
\hline 8. Positive reappraisal & $9.42 \pm 3.90$ & $2-19$ \\
\hline
\end{tabular}

Table (4): Correlations between coping strategies and burden among caregivers of patients with mood disorders.

\begin{tabular}{|c|c|c|c|c|}
\hline \multirow[t]{3}{*}{ Coping Strategies } & \multicolumn{4}{|c|}{ Burden } \\
\hline & \multicolumn{2}{|c|}{ Frequency } & \multicolumn{2}{|c|}{ Bother or upset } \\
\hline & r-value & P-value & r-value & P-value \\
\hline Confrontive coping & 0.076 & 0.450 & 0.090 & 0.375 \\
\hline Distancing & 0.142 & 0.159 & 0.165 & 0.100 \\
\hline Self-controlling & 0.311 & $0.002 *$ & 0.261 & 0.009* \\
\hline Seeking social support & -0.196 & 0.051 & -0.089 & 0.381 \\
\hline Accepting responsibility & 0.158 & 0.116 & 0.197 & $0.049^{*}$ \\
\hline Escape avoidance & 0.121 & 0.231 & 0.029 & 0.774 \\
\hline Planful problem solving & 0.363 & 0.000* & 0.416 & 0.000* \\
\hline Positive reappraisal & 0.245 & 0.014* & 0.252 & 0.011* \\
\hline
\end{tabular}

$$
* \mathrm{P} \leq 0.05
$$

Table (1) shows socio-demographic characteristics of the caregivers of mood disorder patients. The mean age (range) of the caregivers of was $42.57 \pm 13.54$ $(16-75), 53.0$ of them were females, $67.0 \%$ were married and $51.0 \%$ of were illiterate, read \& write, 40.0 were housewives, $65.0 \%$ were from urban areas. In relation to consanguinity, it was noticed that $79.0 \%$ were from first degree relatives.

Table (2) reveals distribution of the mean scores and standard deviations of mood disorder burden index among caregivers of mood disorder patients. It was found that, the highest mean scores of frequency of exhibited specific behaviors by patients were related to sleeping too much $(2.45 \pm 1.52)$, that patients said there were too many thoughts running through their head $(2.05 \pm 1.51)$ and they were more talkative than usual $(2.05 \pm 1.51)$. While; the highest mean scores of the caregivers' specific experiences related to the patients were that caregiver felt that efforts to be helpful to patient when patient was having mood problems were rejected $(2.03 \pm 1.40)$, caregiver felt that patients had withdrawn from caregiver as a result of patient's mood disorder $(2.02 \pm 1.46)$ and caregiver felt a loss of companionship or closeness with patient as a result of patient's mood disorder $(2.01 \pm 1.52)$. Also, this table shows that, the highest mean scores of the caregivers' burden (Bother or upset) were related to sleeping too much (2.25 \pm
$1.15)$, caregiver felt that patients had withdrawn from caregiver as a result of patient's mood disorder (2.10 \pm 1.01 ), caregiver felt that efforts to be helpful to patient when patient was having mood problems were rejected $(2.06 \pm 1.05)$ and caregiver felt a loss of companionship or closeness with patient as a result of patient's mood disorder $(2.03 \pm 1.20)$.

Table (3) reveals the total mean scores of each subscale of coping strategies among caregivers of mood disorder patients. It was found that, the highest mean scores were related to self-controlling (9.89 \pm $4.01)$, positive reappraisal $(9.42 \pm 3.90)$ and seeking social support $(9.25 \pm 4.43)$. Then followed by escape/ avoidance $(8.52 \pm 2.96)$ and distancing (8.22 \pm 3.12 ) respectively.

Table (4) illustrates the correlation between coping strategies and burden among caregivers of mood disorder patients. It was found that, self-controlling, planful problem solving and positive reappraisal were positively and significantly correlated with frequency of exhibited specific behaviors by patients ( $\mathrm{r}=0.311$, $0.363, \& 0.245$ with $\mathrm{p}$-value $=0.002,0.000 \& 0.014)$ respectively. Also, they were positively and significantly correlated with the caregivers' bother or upset $(\mathrm{r}=0.261,0.416 \& 0.252$ with $\mathrm{p}$-value $=0.009$, $0.000 \& 0.011)$ respectively. However, seeking social support was negatively and non-significantly correlated with frequency of exhibited specific 
behaviors by patients and caregivers' bother or upset. $(\mathrm{r}=-0.196 \&-0.089$ with $\mathrm{p}$-value $=0.051 \& 0.381)$ respectively.

\section{Discussion}

The current study showed that the caregivers of patients with mood disorder experienced highest mean of burden related to the frequency of symptoms exhibited by patients and caregivers bother or upset as sleeping too much, too many thoughts running through their head and they were more talkative than usual. Also, they experienced high burden related to their experience with patients like that, caregiver felt that efforts to be helpful to patient when he/she was having mood problems were rejected, caregiver felt that patients had withdrawn from caregiver as a result of patient's mood disorder and caregiver felt a loss of companionship or closeness with patient as a result of patient's mood disorder. This could be attributed to that these symptoms lead to poorer social and occupational functioning for both patients and their caregivers or could be related to the characteristics of the caregivers as more than half of them were illiterate/ read and write and less than half of them were housewives who have other household duties .

The current finding is supported by Pompili et al., (2014) who suggested that caregiver burden is high in bipolar disorder. Also, this finding is partially supported by Da Silva et al., (2014) who found that, the mean burden was slightly higher among the caregivers of individuals with bipolar disorder, which is in accordance with other studies (Heru \& Ryan, 2004; Ogilvie et al., 2005; Weinstock, et al., 2006). Similarly, Reinares et al., (2006) reported that, subjective burden for the caregiver was the source of moderate distress highly related to the patient's behavior, followed by the adverse effects on others; nearly $70 \%$ of caregivers were distressed by the way the illness had affected their own emotional health and their life in general. The patient's role performance was a source of lower distress level. Moreover, (Perlick et al., (2005), Perlick et al., 2007) and Perlick et al., 2008) reported that, caregivers of patients with bipolar disorder, similar to caregivers of patients with other major affective or chronic psychiatric disorders, report high levels of stress and poorer general health, increased visits to their primary care physicians, and higher numbers of symptoms of physiological and psychological conditions, including depressed mood, when compared to caregivers who report less stress.

In another study carried out by Ahmed (2011), it was found that, caregivers of bipolar mood disorder (manic) patients having more severe burden than any other form of mood disorders. Abiodun et al., (2010) found $60.7 \%$ caregiver of patients with mental illness had severe burden. However, Awad et al., (2010) found $37 \%$ caregivers of disabled elderly had significant burden. They infer that caregiver of mood disorders possessed more burden than the caregivers of disabled elder persons and Vasudeva et al., (2013) reported that, the families of both schizophrenia and bipolar disorder experience considerable burden. The extent of burden in relatives of schizophrenia was, however, significantly higher than that in bipolar disorder. However, Swapna et al., (2012) concluded that, there was no difference between burden experienced by the caregivers of bipolar affective disorder and alcohol dependence syndrome.

Concerning coping strategies among caregivers of mood disorder patients; the present study revealed that the highest mean scores were related to selfcontrolling, positive reappraisal and seeking social support. This could be explained by that more than half of the caregivers were females who used selfcontrolling to cope with stressful situations or could be related to cultural differences as in Upper Egyptian culture social support is utilized more than any other coping strategies and there is more social network than any other region. Then followed by escape/ avoidance and distancing respectively. This finding is supported by (Hassan et al., 2011) who found that, the most coping strategies used by caregivers of schizophrenic patients were selfcontrolling, positive reappraisal and escapeavoidance. This accordance in results could be attributed to using of the same instrument of coping strategies.

Also, the current study finding is partially supported by McCubbin et al., (199) who reported that, some family members with mentally ill relatives use avoidant strategies and social support to cope with their situation. Avoidance is an emotion-focused coping strategy that some families use when they overestimate the threat of the illness or underestimate their own coping ability. Social support is described as an exchange of information by individuals, which provides emotional support, esteem support, and network support. However, the current finding is contradicted with National Alliance on Mental Illness (2010) that reported some families use religious and spiritual support as a means for coping with caring for a mentally ill relative. The use of spirituality is seen as a positive emotion-focused coping strategy.

Overall, family members of inpatient psychiatric patients coped more effectively with emotion-focused coping strategies, which included communicating with family, cognitive distraction (passive appraisal), cognitive restructuring (acceptance of problem), and spirituality (Chandrasekaran et al., 2002 and Eaton et al., 2011). On the other hand, a study 
conducted in India indicated that problem centered coping approaches were rather applied by bipolar patients' caregivers and emotional-centered coping approaches were rather applied by schizophrenic patients' caregivers (Chakrabarti \& Gill, 2002).

Contrary to a study carried out by Kumar\& Saini (2012), it was noticed that, caregivers adopt positive cognitive coping strategies followed by distraction and problem-solving to overcome burden due to patient's illness. It was also found that external attribution such as blaming own fate and holding other people responsible for the situation were among the least used coping strategies used by caregivers.

The current study illustrated that, self-controlling, planful problem solving and positive reappraisal were positively and significantly correlated with frequency of exhibited specific behaviors by patients and caregivers' bother or upset. However, seeking social support was negatively and non-significantly correlated with frequency of exhibited specific behaviors by patients and caregivers' bother or upset. This could be explained by that social support as a coping strategy helps in expressing and ventilating emotions and consequently lessening the sense of bother or upset. This finding is partially in agreement with (Hassan et al., 2011) who found burden was negatively and non-significantly correlated with confrontive coping, distancing, seeking social support and positive reappraisal coping strategies. However, it was positively and non-significantly correlated with self-controlling, accepting responsibility, escapeavoidance and planful problem solving.

Contrary to the current study finding, Kumar\& Saini (2012) found that the type of coping strategies used was not associated with the extent of burden.

\section{Conclusions}

Caregivers of patients with mood disorder experienced high mean scores of burden related to the frequency of symptoms exhibited by patients and caregivers' bother or upset and their experience with patients. The highest mean scores of coping strategies utilized by them were related to self-controlling, positive reappraisal and seeking social support, escape/ avoidance and distancing respectively. Selfcontrolling, planful problem solving and positive reappraisal were positively and significantly correlated with frequency of exhibited specific behaviors by patients and caregivers' bother or upset. However, seeking social support was negatively and non-significantly correlated with them.

\section{Recommendations:}

Designing and implementing psychoeducational programs are essential for caregivers of patients with mood disorders to provide them information, support and stress management skills and healthy coping strategies.

\section{References}

1. Abiodun, O., Olugbenga, A., Adebayo, R., (2010): Psychopathology and subjective burden amongst primary caregivers of people with mental illness in South-Western Nigeria', Social Psychiatry and Psychiatric Epidemiology, vol. 80, pp. 54-9.

2. Ahmed H., (2011): Burden among caregivers of patients with mood disorders. Available at: http://www.diplomarbeiten24.de/vorschau/265 489.html

3. Ampalam; P., Gunturu; S., \& Padma; A., (2012): Comparative study of caregiver burden in psychiatric illness and chronic medical illness. 2012 | Vol: 54 | Issue: 3 | Page: 239-243.

4. Awad, M., Gammal, H., Fahmy, M., Imam E., (2010), 'Determinants of disabled elderly caregivers burden in Ismailia, Egypt' Medical Journal of Cairo University, Vol. 78, No. 2, pp. 31-7.

5. Chakrabarti S., Gill S., (2002): Coping and its correlates among caregivers of patients with bipolar disorder: a preliminary study. Chandigarh, India. medinst@pgi.chd.nic.in Bipolar Disord. Feb; 4(1):50-60.

6. Chandrasekaran R., Sivaprakash B., Jayestri S., (2002): Coping strategies of the relatives of schizophrenic patients. Indian J Psychiatry, 44 (1):9-13.

7. Da Silva G., Karen Jansen, Barbosa L., Branco J., Pinheiro RT, Da Silva PV, Kapczinski F and Da Silva RA (2014): Burden and related factors in caregivers of young adults presenting bipolar and unipolar mood disorder. Int J Soc Psychiatry 60: 396 originally published online 3 July 2013 DOI: 10.1177/0020764013491740, 396- 402.

8. Davenport L., (2008): Patient depression predicts bipolar disorder caregiver burden. Acta Psychiatr Scand; 118: 49-56.

9. Eaton P., Davis B., Hammond P., Condon E., and McGee Z., (2011): Coping strategies of family members of hospitalized psychiatric patients. Nursing Research and Practice Volume 2011, Article ID 392705, 12 pages doi:10.1155/2011/392705.

10. Folkman, S., Lazarus, R., S.,Dunkel-Schetter, C., Delongis, A., \& Gruen, R.(1986): The dynamics of a stressful encounter: Cognitive appraisal coping and encounter outcomes. Journal of Personality and Social Psychology, 50, 992-1003. 
11. Hassan W., Mohamed I., Abd Elnaser A., \& Sayed N., (2011): Burden and coping strategies in caregivers of schizophrenic patients. Journal of American Science, 2011; 7(5), 802-811.

12. Heru, A., \& Ryan, C., (2004). Burden, reward and family functioning of caregivers for relatives with mood disorders: 1-year follow-up. Journal of Affective Disorders, 83, 221-225.

13. Martire L., Hinrichsen G., Morse J., Reynolds C., Gildengers A., Mulsant B., \& Schulzr R., (2009): The Mood Disorder Burden Index: A scale for assessing the burden of caregivers to adults with unipolar or bipolar disorder. Psychiatry Res. Jun 30; 168 (1): 67- 77.

14. McCubbin H., Olson D., H., and Larsen A., (1991): "F-COPES: Family crisis oriented personal evaluation scales," in Family Assessment Inventories for Research and Practice, H. I. McCubbin and A. I. Thompson, Eds., pp. 203-218, University of WisconsinMadison, Madison, Wis, USA, 2nd edition,.

15. Moller-Leimkuhler A., (2005): Burden of relatives and predictors of burden. Baseline results from the Munich 5-year-follow-up study on relatives of first hospitalized patients with schizophrenia or depression. Eur Arch Psychiatry Clin Neurosci.; 255(4): 223-231. Epub 2004/11/19.

16. Moller-Leimkuhler A., Obermeier M., (2008): Predicting caregiver burden in first admission psychiatric patients: 2 year follow up results. Eur Arch Psychiatry Clin Neurosci; 258, 406- 413.

17. Muscroft J., Bowl R., (2000): The impact of depression on caregivers and other family members: Implications for professional support. Couns Psychol Q;13:117-34.

18. National Alliance on Mental Illness (2010): "Federal response to the funding crises in state and local mental health services".

19. Ogilvie, A., Morant, N., \& Goodwin, G., (2005). The burden on informal caregivers of people with bipolar disorder. Bipolar Disorders, 7 Suppl 1, 25-32.

20. Ostman M, Hansson L., (2001): The relationship between coping strategies and family burden among relatives of admitted psychiatric patients. Scand J Caring Sci.; 15(2): 159-164. Epub 2002/06/25.643.

21. Perlick D., Hohenstein J., Clarkin J., Kaczynski R., Rosenheck R., (2005): Use of mental health and primary care services by caregivers of patients with bipolar disorder: a preliminary study. Bipolar Disord. ; 7:126-135.

22. Perlick, D., Rosenheck, R., Miklowitz, D., Chessick, C., Wolff, N., Kaczynski, R., Ostacher, M., Patel, J., Desai, R., (2007a.): The
STEP-BD Family experience collaborative study group. Prevalence and correlates of burden among caregivers of patients with bipolar disorder enrolled in the systematic treatment enhancement program for bipolar disorder. Bipolar Disord. 9, 262-273.

23. Perlick D., Rosenheck R., Miklowitz D., Kaczynski R., Link B., Ketter T, Wisniewski S, Wolff N, Sachs G.,( 2008): Caregiver burden and health in bipolar disorder: a cluster analytic approach. J Nerv Ment Dis.; 196: 484-491.

24. Pompili, M., Harnic, D., Gonda, X., and Girardi, P.(2014): Impact of living with bipolar patients: Making sense of caregivers' burden. World J Psychiatry. Mar 22, 2014; 4(1): 1-12.

25. Pratima, Bhatia, \& Jena (2011): Caregiver burden in severe mental illness. Delhi Psychiatry Journal 2011; 14: (2) (C) Delhi Psychiatric Society, 2011- 2013.

26. Reinares, M., Vieta, E., (2004): The burden on the family of bipolar patients. Clin Approach Bipolar Disord 3, 17-23.

27. Reinares M., Vieta E., Colom F., MartínezArán A., Torrent C., Comes M., Goikolea J., Benabarre A., Daban C., Sánchez-Moreno J., (2006): What really matters to bipolar patients' caregivers: sources of family burden. J Affect Disord.; 94:157-163.

28. Rudnick A., (2004): Burden of caregivers of mentally ill individuals in Israel: A family participatory study. International Journal of Psychosocial Rehabilitation.9 (1), 147-152.

29. Scazufca M., Kuipers E., (1999): Coping strategies in relatives of people with schizophrenia before and after psychiatric admission. British Journal of Psychiatry; 174:154-58.

30. Swapna B., Sudarshan C, and Shamshad B., (2012): Burden on caregivers in bipolar affective disorder and alcohol. Int J Biol\& Med Res. 3 (3):1992- 1997.

31. Vasudeva S., Sekhar CK., and Rao PG (2013): Caregivers burden of patients with schizophrenia and bipolar disorder: A sectional study. Indian J Psychol Med. Oct-Dec; 35(4): 352-357. doi: 10.4103/0253-7176.122224.

32. Weinstock, L., Keitner, G., Ryan, C., Solomon, D., \& Miller, I., (2006). Family functioning and mood disorders: A comparison between patients with major depressive disorder and bipolar I disorder. Journal of Consulting and Clinical Psychology, 74, 1192-1202. 